\title{
Development of predictive models for the specific energy in indentation of rocks
}

\author{
Balla Kalyan, CSN Murthy and RP Choudhary \\ National Institute of Technology \\ Surathkal, India \\ bkalyan70@gmail.com
}

\begin{abstract}
This paper presents an experimental study on the static indentation tests on six types of rocks namely marble, limestone, basalt, steel gray granite, moon white granite and black galaxy granite using commercial drill bits (indenters) of spherical button type of $35 \mathrm{~mm}, 38 \mathrm{~mm}, 45 \mathrm{~mm}$ and $48 \mathrm{~mm}$ diameter to determine specific energy at four index (rotation) angles viz 100, 200, 300, 400. The influence of the operating variables like diameter of indenter (drill bit), index angle and rock properties on the specific energy were investigated and analysed. Statistical analyses were employed to determine the most significant operating variables and rock properties influencing the specific energy and the models were built for the estimation of specific energy depending on the operating variables and the rock properties. Moreover, the derived models were validated through statistical tests such as the determination coefficient, VAF (Variation Account For), Root Mean Squared Error (RMSE) and Mean Absolute Percentage Error (MAPE). The results indicated that the specific energy varied with the change in diameter of indenter and index angle. It was concluded that the specific energy varies with variation of physico-mechanical properties of rocks.
\end{abstract}

Keywords - indentation; specific energy; index angle; micro controller compressive testing machine

\section{INTRODUCTION}

Rock indentation is the fundamental process for rock excavation and fragmentation by using mechanical excavation methods. Therefore, it is necessary to investigate the basic deformation and failure mechanisms during the process of rock indentation [1]. Also, it is very much essential to know the process of indentation to assess the drill/cutting machine performance and also to know the strength of rocks for the suitability of drill/cutting picks for particular type of rocks [2].

Different methods of excavation utilise different mechanisms to loosen or excavate a rock body, and various rock types exhibit different strengths against fracturing [3].. Therefore the phenomenon of fracturing of rocks with different mechanisms and tools has to be studied theoretically and experimentally to design the tools for mechanical excavation. Designing faster and efficient excavation systems and developing accurate and reliable performance prediction models would improve the success of mechanical mining [4].
The specific energy is one of the most important performance indicators in drilling and cutting processes. It is derived from the amount of energy required to remove a given volume of rock and has been successfully used for the performance evaluation of drill bits and circular diamond sawblades. The lower value of specific energy indicates that the drilling/sawing is performed more efficiently [5].

As well known, it is very hard to build models for the performance prediction, valid for all rock types since the effect of process parameters on drilling/sawing performance varies from one rock type to another even in different samples of the same rock type. However, the study aimed at developing models for the estimation of the specific energy from operating parameters and physico-mechanical properties of rocks.

\section{EXPERIMENTAL SET UP AND EXPERIMENTAL PROCEDURE}

\section{A.Experimental set up}

Static indentation tests were conducted on a micro controller compression testing machine of $2000 \mathrm{kN}$ capacity. An indenter (drill bit) holder was fabricated for compression testing machine as shown in the "Fig.1". At one end of the indenter holder, the different types of drill bits were attached by clamp and screw arrangement. The rock blocks were confined inside a specimen box which was fabricated specially for this purpose as shown in the "Fig.2", and rigidly held on four sides with the help of nut and bolt arrangement. This specimen box was placed on the top of the bottom platen of the compression testing machine during the test. Similarly a digital dial gauge was attached to the magnetic holder and the assembly is mounted to the side plate of the testing machine. The total set up is shown in "Fig.3".

\section{B. Experimental procedure}

Indentation tests were conducted on the rock types considered for the present work. These tests were carried out at four indexing angles viz 10 degrees, 20 degrees, 30 degrees and 40 degrees for $35 \mathrm{~mm}, 38 \mathrm{~mm}, 45 \mathrm{~mm}, 48 \mathrm{~mm}$ diameter of spherical button bit [6].

To carry out static tests, cubical blocks $(0.127 \mathrm{~m}$ length $\times 0.1524 \mathrm{~m}$ width $\times 0.2032 \mathrm{~m}$ height) were prepared with the help of a rock cutting machine, from the rock blocks 


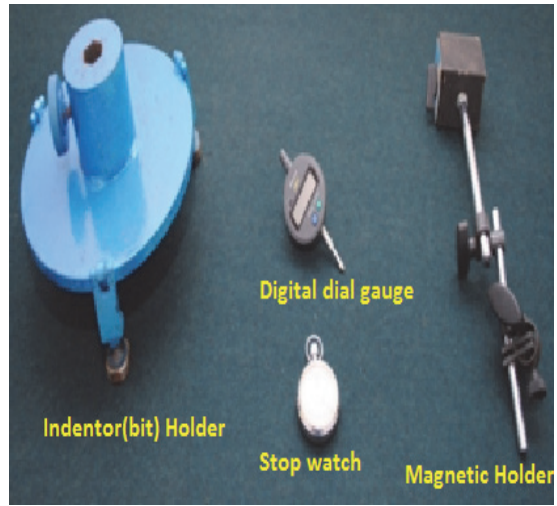

Fig. 1. Indenter (bit) Holder, Digital Dial Gauge Magnetic Holder and Stop Watch used in test

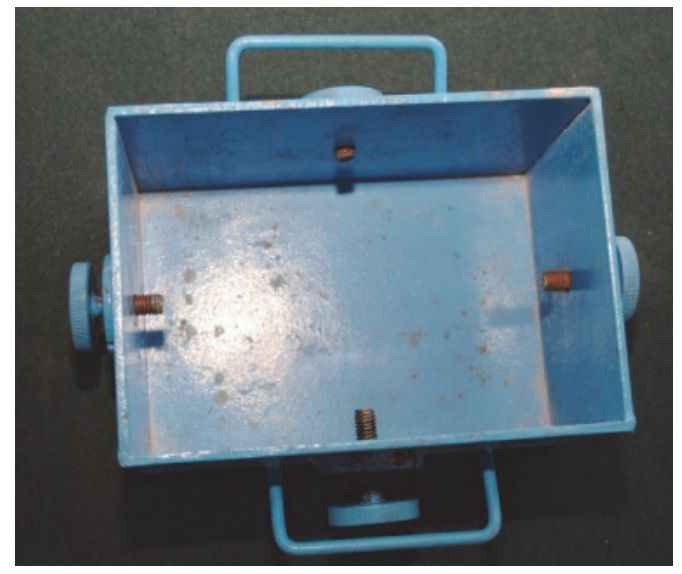

Fig.2. Specimen box

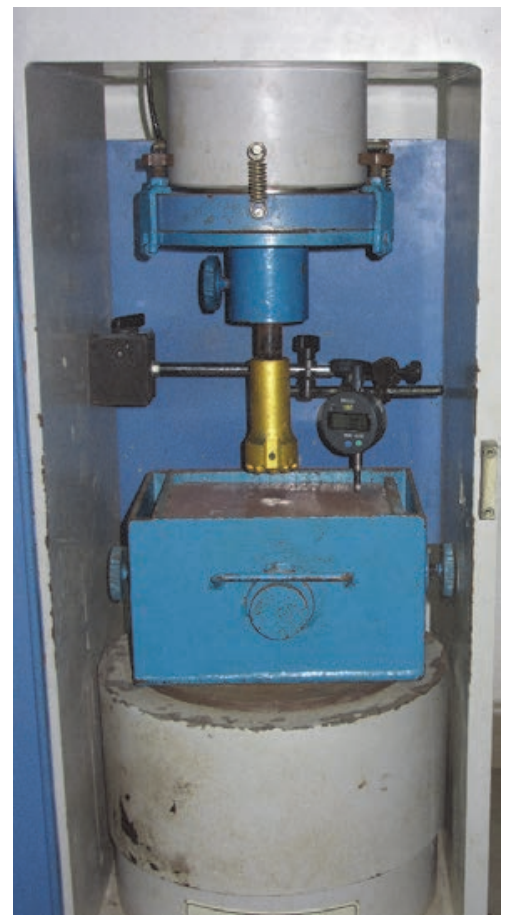

Fig. 3. Experiment Set up collected from various Indian mines/quarries in India. They were polished to produce perfectly parallel and mutually perpendicular faces

Static indentation test were conducted on a Microprocessor compression testing machine $(2000 \mathrm{kN})$ capacity). A bit holder was fabricated as indicated in the "Fig.1". At one end of the bit holder, the different types of drill bits were attached by clamp and screw arrangement. The rock blocks were confined inside a specimen box as indicated in the "Fig.2" and rigidly held on four sides with the help of nut and bolt arrangement. This specimen box was placed on the top of the bottom platen of the compression testing machine during the test.

All rock samples are marked with lines of $0^{0}, 10^{\circ}, 20^{\circ}$, $30^{\circ}$ and $40^{\circ}$ index angles. Then rock sample with above markings was placed in the Specimen Box and thoroughly clamped with packing materials and with the help of nuts and bolts. The complete assembly of Specimen Box along with the rock sample was placed on the top of the bottom platen of the testing machine. The bit holder, assembly fabricated for this purpose, attached at the bottom of the upper platen, and the length adjusted for the bit to rest on the surface of the rock sample. During testing, for applying the axial compressive load, the bottom platen was moved up, so that the bit was pressed onto the rock the situation as prevailing in actual drilling. The static indentation tests were conducted at a rate of loading $0.1 \mathrm{kN} / \mathrm{sec}$, which was kept constant for all the experiments. This rate chosen is within the acceptable static range and as per ISRM guide lines [7].

A digital dial gauge with a least count of $0.01 \mathrm{~mm}$, was attached, with help of magnetic holder attached to side frame of the compression testing machine and it is adjusted that the tip of its needed touched the top surface of the rock sample, to measure the depth of penetration of the bit into the rock during each cycle of loading and unloading. The sample was loaded continuously for 60 seconds for all the bit-rock combinations. At every 5 seconds force (from control unit) and penetrations (from dial gauge) readings were taken during the loading and loadings. However, unloading time varied depending upon the bit-rock combinations. The time during loading and unloading was carefully recorded with the help of a stop watch.

The procedure followed for every loading and unloading in each indentation, and rock chips were collected so formed during indentation. Then the Specimen Box containing the rock sample was rotated through the new indexing angle before new indentation was made. For each indexing angle, three indentations, each time on new rock sample, were made and the average of these three results were considered for calculating the energy under Force-penetration (F-P) curve.

The volume of the crater was calculated by dividing the weight of the rock chips and its powder collected from the crater by the density of the rock. The volumes of very few craters were also measured using dental wax was pressed into the crater and the volume of the wax forming the crater was determined using water displacement method. The volume calculated from the weight of the rock chips and its 
powder was found to be approximately $2 \%$ higher than that obtained by the dental wax method. Therefore, the crater volumes were calculated using the weight of the rock chips and powder generated during the static indentation tests for all the bit- rock combinations. Force-Penetration curves (F-P curves) are plotted using MATLAB software for all the bitrock combinations. The energy expended in each test is the area under the force-penetration curve. This area was measured using a planimeter. The ratio of the expended energy to the crater volume is the specific energy, which is the energy required to break out a unit volume of rock, was determined for all the bit-rock combinations.

Table I. Specific Energy Values For Spherical Button Bit Of DIFFERENT DIAMETERS

\begin{tabular}{|c|c|c|c|c|c|}
\hline \multirow[b]{2}{*}{ Rock } & \multirow[b]{2}{*}{$\begin{array}{l}\text { Index } \\
\text { Angle }\end{array}$} & \multicolumn{4}{|c|}{ Specific Energy $(\mathrm{Nm} / \mathrm{m} 3) \times 10^{7}$} \\
\hline & & $\begin{array}{l}48 m m \\
\text { dia }\end{array}$ & $\begin{array}{l}45 \mathrm{~mm} \\
\text { dia }\end{array}$ & $\begin{array}{l}38 m m \\
\text { dia }\end{array}$ & $\begin{array}{l}35 \mathrm{~mm} \\
\text { dia }\end{array}$ \\
\hline \multirow{4}{*}{ Marble } & 10 & 12.46 & 15.83 & 18.40 & 21.44 \\
\hline & 20 & 9.42 & 12.52 & 15.77 & 18.01 \\
\hline & 30 & 7.60 & 10.10 & 13.75 & 15.24 \\
\hline & 40 & 12.71 & 14.43 & 18.15 & 21.98 \\
\hline \multirow{4}{*}{ Limestone } & 10 & 8.71 & 12.02 & 15.08 & 17.69 \\
\hline & 20 & 7.86 & 10.32 & 13.05 & 14.07 \\
\hline & 30 & 7.18 & 9.17 & 11.82 & 13.31 \\
\hline & 40 & 9.92 & 12.27 & 16.38 & 20.15 \\
\hline \multirow{4}{*}{ Basalt } & 10 & 48.60 & 61.01 & 62.29 & 63.20 \\
\hline & 20 & 42.53 & 53.61 & 53.78 & 56.83 \\
\hline & 30 & 49.90 & 64.27 & 63.18 & 67.10 \\
\hline & 40 & 55.28 & 71.61 & 69.46 & 75.05 \\
\hline \multirow{4}{*}{$\begin{array}{l}\text { Steel } \\
\text { Gray } \\
\text { Granite }\end{array}$} & 10 & 38.94 & 52.49 & 49.20 & 50.28 \\
\hline & 20 & 32.96 & 43.57 & 41.65 & 41.61 \\
\hline & 30 & 37.97 & 49.24 & 49.81 & 49.37 \\
\hline & 40 & 43.23 & 55.04 & 57.49 & 57.15 \\
\hline \multirow{4}{*}{$\begin{array}{l}\text { Moon } \\
\text { White } \\
\text { Granite }\end{array}$} & 10 & 42.41 & 55.86 & 53.10 & 53.19 \\
\hline & 20 & 34.82 & 45.59 & 46.13 & 45.98 \\
\hline & 30 & 43.10 & 54.04 & 54.96 & 53.68 \\
\hline & 40 & 47.82 & 61.86 & 61.69 & 60.80 \\
\hline \multirow{4}{*}{$\begin{array}{l}\text { Black } \\
\text { Galaxy } \\
\text { Granite }\end{array}$} & 10 & 45.87 & 58.59 & 59.07 & 61.76 \\
\hline & 20 & 39.72 & 50.22 & 49.83 & 53.59 \\
\hline & 30 & 47.92 & 59.37 & 57.64 & 61.08 \\
\hline & 40 & 53.89 & 66.26 & 66.12 & 67.97 \\
\hline
\end{tabular}

\section{Determination of Physico-Mechanical Properties}

The physico-mechanical properties of the rocks determined in laboratory are presented in Table II. The physico-mechanical properties of rocks like density, hardness(SRN), uniaxial compressive strength (UCS), Brazilian tensile strength (BTS), abrasion resistance, Young's Modulus and Poisson's ratio as per the suggestive methods laid by International Society for Rock Mechanics [8].

\section{Determination of Uniaxial Compressive Strength}

To determine the Uniaxial Compressive Strength (UCS) of the rock samples, $54 \mathrm{~mm}$ diameter NX-size core specimens, having a length-to-diameter ratio of 2.5 to 3 : 1 . Load was applied continuously at a stress rate $0.5 \mathrm{MPa} / \mathrm{s}$ until the failure occurred. The maximum load (in $\mathrm{kN}$ ) at failure was recorded. The uniaxial compressive strength of the specimen was calculated by dividing the maximum load carried by the specimen during the test, by the original cross-sectional area.

\section{Determination of Brazilian Tensile Strength}

To determine the Brazilian tensile strength of the rock samples, $54 \mathrm{~mm}$ diameter NX- size core specimens, having a length (thickness) less than $27 \mathrm{~mm}$ were prepared as per ISRM suggestions. The test specimen was placed between the two steel loading jaws in the testing machine in such a way that the load transfer system is properly aligned. The tensile load on the specimen was applied continuously at stress rate of $200 \mathrm{~N} / \mathrm{s}$ until sample failed. The maximum load (in $\mathrm{kN}$ ) at failure was recorded. The tensile strength of the specimen was calculated by dividing the maximum load applied to the specimen by the original cross-sectional area.

\section{Determination of dry density of rocks}

The volume of a sample may be determined by water displacement. The specimen is dropped under water and its volume determined from the displaced water volume. A graduated measuring container was used for this purpose. Density is a mass per unit volume of rock. Initially the weight of the sample was measured. The initial reading of water level (height of water column) in the graduated container was taken. Then the sample was dropped slowly in the water container. The final reading of height of water column in graduated container was taken. Difference of the two readings was the volume of water displaced. The density data of sample was obtained from measurement of volume and mass and volume of each sample and using the following formula.

Density $(\mathrm{g} / \mathrm{cc})=$ mass of the sample/ volume of sample.

\section{Determination of Hardness of rocks}

All the tests were carried out with the hammer held vertically downwards and at right angles to horizontal faces of large rock blocks. The tests were performed by an $\mathrm{N}$ type Schmidt hammer with an impact energy of $2207 \mathrm{Nm}$. All the tests were carried out with the hammer held vertically downwards and at right angles to horizontal faces of large rock blocks. The tests were performed by an $\mathrm{N}$ type Schmidt hammer with an impact energy of $2207 \mathrm{Nm}$.

For data gathering, 20 rebound values, as recommended by the ISRM suggested method, were taken from single impacts separated by a plunger diameter of $15 \mathrm{~mm}$. The mean of 20 readings is the hardness of the specimen [9].

\section{Determination of Young's Modulus of the rock}

The rock samples, $54 \mathrm{~mm}$ diameter NX-size core specimens, having a length-to-diameter ratio of 2.5 to 3 : 1 , 
were used for the test. The oven-dried and NX-size core samples were tested by using a microcontroller compression testing machine in the Rock Mechanics Laboratory. A dial gauge was used for measuring the axial strain. An arrangement to mount the dial gauge was fixed to the sample during testing. Load was applied continuously at a stress rate $0.5 \mathrm{MPa} / \mathrm{s}$ until the failure occurred. The load was applied generally up to $70 \%$ of the compressive strength. Loads and axial or deformations were recorded at evenly spaced load intervals during the test. Ten readings were taken over the load range to define the axial stress-strain curves. Then, the Young's Modulus of the specimen was calculated by dividing the ratio of the axial stress change to axial strain produced by the stress change.

\section{Determination of Poisson's Ratio}

The rock samples, $54 \mathrm{~mm}$ diameter NX-size core specimens, having a length-to-diameter ratio of 2.5 to $3: 1$, were used for the test. Two dial gauges were used for axial and circumferential strains. The oven-dried and NX-size core samples were tested by using a microcontroller compression testing machine in the Rock Mechanics Laboratory. Load was applied continuously at a stress rate $0.5 \mathrm{MPa} / \mathrm{s}$ until the failure occurred. The load was applied generally up to $70 \%$ of the compressive strength. The applied loads and axial $\left(\varepsilon_{\mathrm{a}}\right)$ and circumferential/diametrical strains $\left(\varepsilon_{\mathrm{d}}\right)$ or deformations were recorded at evenly spaced load intervals during the test.. At least ten readings should be taken over the load range to define the axial and diametric stress-strain curves.

Poisson's ratio was calculated from the equation

$\mathbf{v}=$-(slope of axial stress-strain/slope of diametrical stress)

\section{Determination of Abrasion Resistance of Rocks}

Los Angeles abrasion test was used for determination of abrasivity of all the rocks in the present study. The abrasive charge and the test sample used are dependent on the aggregate size and grading. The coarse aggregate of four sizes for the test are as per ISRM standards

\section{DEVELOPMENT OF PREDICTIVE MODELS}

A computing Minitab 17 program was used for the statistical analysis. Multi-variable linear regression analysis

was carried out to predict the specific energy.
A number of statistical parameters or terms are associated with multi-variable linear regression analysis were demined. Predictors that were used in multiple linear model of SE are diameter of drill bit, index angle, density, compressive strength, tensile strength, Abrasion resistance, SRN, Young's Modulus and Poisson's ratio.

For the development of regression models for all the bits, $70 \%$ of the data (66 data sets) have been considered for training and $30 \%$ of the data (30 data sets) have been considered for testing.

Regression Equation: Specific energy $=3746-0.712$ Diameter of the bit +0.3662 Index angle -1058 Density -

82.0 Compressive strength - 4.32 Hardness(SRN) +638 Tensile strength - 29.98 Abrasion resistance 16.72 Young's Modulus + 4684 Poisson's Ratio.

\section{RESULTS AND DisCUSSIONS}

\section{A. Residual Plots for Specific energy}

Histogram of the Residuals is an exploratory tool to show general characteristics of the residuals including typical values, spread, and shape. All models showed equal distribution and no outliers which indicate the regression models developed are good "Fig. 6 \&7".

Normal Probability Plot of residuals. The points in the plot should form a straight line indicating that the residuals are normally distributed. All models showed the above trends which indicate the regression models developed are good "Fig. 6 \&7".

Residuals versus Fitted Values. This plot showed a random pattern of residuals on both sides of 0 . If a point lies far from the majority of points, it may be an outlier. There should not be any recognizable patterns in the residual plot. All models showed the above trends which indicate the regression models developed are good "Fig.6 \& 7".

Residuals versus Order of Data. This is a plot of all residuals in the order that the data was collected and can be used to find non-random error, especially of time-related effects. This plot helps us to check the assumption that the residuals are uncorrelated with each other. All models showed the above trends which indicate the regression models developed are good "Fig.6 \&7".

TABle II Physico-Mechanical Properties Of Rocks

\begin{tabular}{|l|l|l|l|l|l|l|l|}
\hline S.No & \multicolumn{1}{|c|}{ Properties of Rocks } & \multicolumn{1}{|c|}{ Marble } & $\begin{array}{c}\text { Limest } \\
\text { one }\end{array}$ & \multicolumn{1}{|c|}{ Basalt } & $\begin{array}{c}\text { Steel } \\
\text { gray } \\
\text { granite }\end{array}$ & $\begin{array}{c}\text { Moon } \\
\text { white } \\
\text { granite }\end{array}$ & $\begin{array}{c}\text { Black } \\
\text { galaxy } \\
\text { granite }\end{array}$ \\
\hline 1 & Density (grams/cm3) & 2.59 & 2.62 & 2.8 & 2.76 & 2.6 & 2.635 \\
\hline 2 & $\begin{array}{l}\text { Uniaxial Compressive Strength } \\
\text { (MPa) }\end{array}$ & 24.52 & 29.55 & 54.13 & 30.597 & 28.831 & 56.977 \\
\hline 3 & Brazilian Tensile Strength (MPa) & 2.58 & 2.66 & 5.58 & 3.096 & 2.98 & 5.831 \\
\hline 4 & Abrasion resistance (\%) & 35.8 & 29.6 & 16.2 & 24.2 & 31.6 & 17.2 \\
\hline 5 & Hardness(SRN) & 46 & 48 & 53 & 56 & 52 & 59 \\
\hline 6 & Young's Modulus & 21.308 & 24.93 & 29.09 & 28.243 & 24.675 & 30.633 \\
\hline 7 & Poisson's Ratio & 0.22 & 0.235 & 0.3 & 0.26 & 0.24 & 0.29 \\
\hline
\end{tabular}




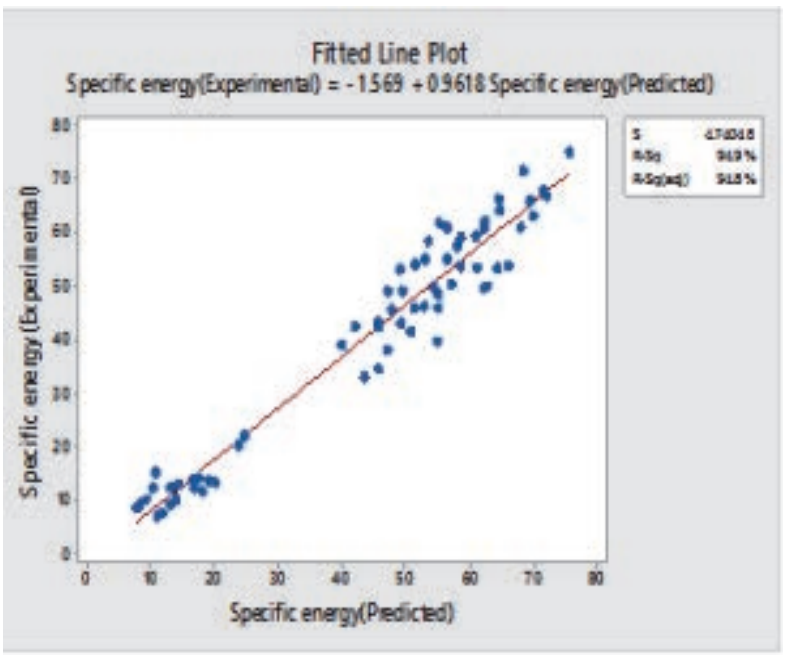

Fig. 4. Predicted SE versus observed SE for the model of spherical button bit for training set

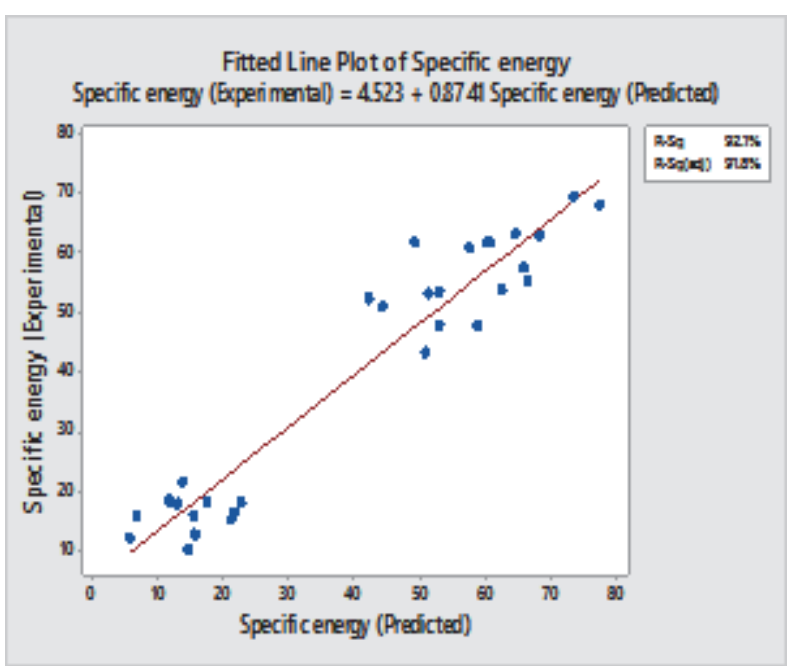

Fig. 5. Predicted SE versus observed SE for the model of spherical button bit for testing set

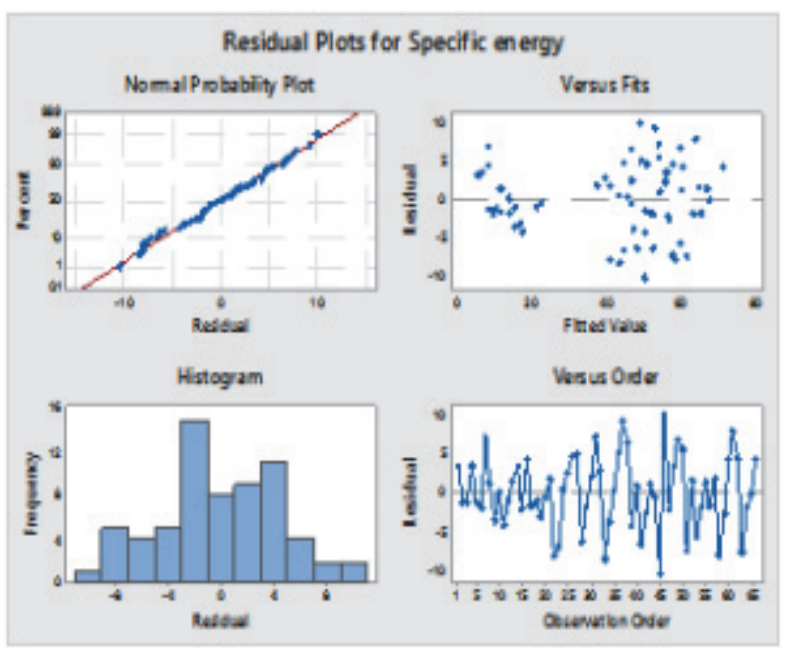

Fig. 6. Residual plots against SE of spherical button bit for training set

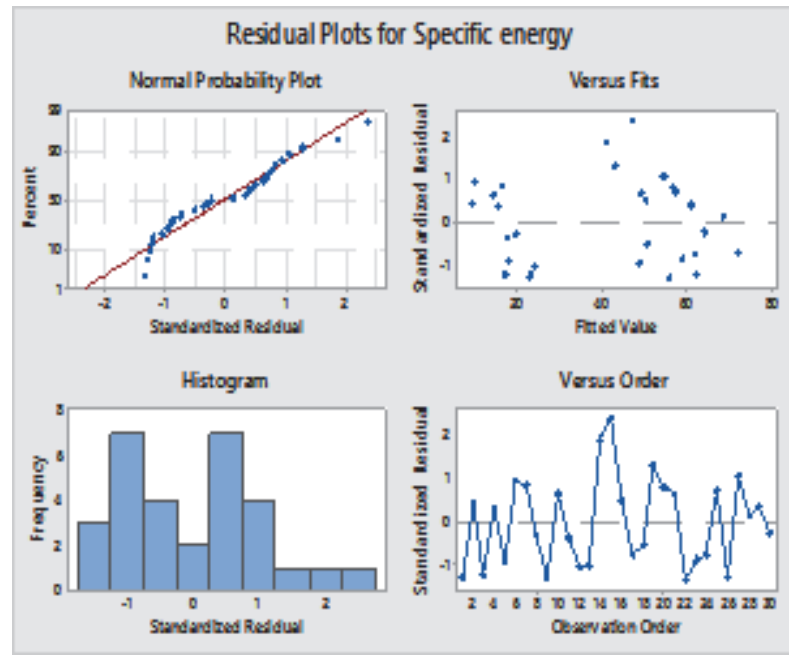

Fig. 7. Residual plots against SE of sphericalbutton bit for testing set

The experimental to predicted and testing values for all the models are shown in "Fig.4\&5", with $\mathrm{r}^{2}$ values 0.92 for spherical button bit which shows that the models are good

\section{B. Performance prediction of the derived models}

In fact, the coefficient of correlation between the measured and predicted values is a good indicator to check the prediction performance of the model. However, in this study, Variation Account For (VAF) and Root Mean Square Error (RMSE) indices were calculated to compare the performance of the prediction capacity of predictive models developed [10], [11],[12],[13],[14] and[15].

$$
V A F=\left[1-\frac{\operatorname{var}\left(y-y^{\prime}\right)}{\operatorname{var}(y)}\right] \times 100
$$

$$
R M S E=\sqrt{\frac{1}{N} \sum_{i=1}^{N}\left(y-y^{\prime}\right)^{2}}
$$

Where $y$ and y' are the measured and predicted values, respectively. If the VAF is 100 and RMSE is 0 , then the model will be excellent. Mean absolute percentage error (MAPE) which is a measure of accuracy in a fitted series value was also used to check the prediction performances of the models. MAPE usually expresses accuracy as a percentage as shown in equation.

$$
M A P E=\frac{1}{N} \sum_{i=1}^{N}\left|\frac{A_{i}-P_{i}}{A_{i}}\right| \times 100
$$

Where $\mathrm{Ai}$ is the actual value and $\mathrm{Pi}$ is the predicted value. Lower values of MAPE indicate that there will be a better correlation between predicted values and experimental results.

Using the developed regression models for bits, performance prediction indices for training as well as test 
data were calculated and are given in Table III. From the table it is evident that the developed models for predicting SE are statistically significant and good.

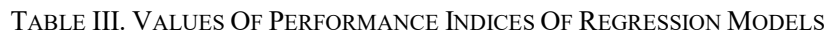

\begin{tabular}{|l|l|l|}
\hline \multicolumn{2}{|l|}{ Performance Indices } & $\begin{array}{l}\text { Spherical } \\
\text { button bit }\end{array}$ \\
\hline \multirow{4}{*}{$\begin{array}{l}\text { Training } \\
\text { data }\end{array}$} & VAF & 95.407 \\
\cline { 2 - 3 } & RMSE & 4.425 \\
\cline { 2 - 3 } & MAPE & 0.161 \\
\hline \multirow{3}{*}{ Test data } & VAF & 90.189 \\
\cline { 2 - 3 } & RMSE & 6.581 \\
\cline { 2 - 3 } & MAPE & 0.194 \\
\hline
\end{tabular}

V. CONCLUSIONS

- The developed regression model results showed that the significant operating variables in rock indentation affecting the specific energy are index angle, diameter of indenter (drill bit) and physico-mechanical properties of the rock.

- Further, the results disclosed that the models derived from the operating variables and rock properties for the estimation of the specific energy have high potentials as a guidance for practical applications.

- Additionally, the results of the current study can provide opportunities to evaluate the drill ability of granitic rocks without drilling tests involving complicated testing procedures.

\section{REFERENCES}

[1] S.Kahraman,, M.Fener and E.Kozman, E" Predicting the Compressive and Tensile Strength of Rocks from Indentation Hardness Index." The Journal of the South African Institute of Mining and Metallurgy. vol.112, pp. 331-339, 2012.

[2] HaoZhang., Ganyun Huang., Haipeng song and Yilan Kang, "Experimental Investigation of Deformation and Failure Mechanisms in Rock under Indentation by Digital Image Correlation." Engineering Fracture Mechanics. vol. 96, pp. 667-675, 2012.

[3] Mohd For Mohd Amin, Chan Sook Huei, Azman Kassim, Mushairry Mustaffa \& Edyonizam Mohammad, "Excavatability of Unclassified Hard Materials” (LPPIM: CREAM/UPP03-02-060111) Final Report, CIDB-CREAM, Kuala Lumpur, 2009.

[4] H. Copur, N.Bilgin,, H.Tuncdemir, and C. Baci,," A Set of Indices Based on Indentation Tests for Assessment of Rock Cutting Performance and Rock Properties." The Journal of the South African Institute of Mining and Metallurgy. vol.0, pp.589-599, 2003.

[5] U.Atici, and A.Ersoy,"Correlation of Specific Energy of Cutting Saws and Drilling Bit with Rock Brittleness and Destruction Energy.”Journal of Materials Processing Technology, vol. 209, pp. 2602-2612, 2009.

[6] Ch.S.N Murthy, "Experimental and theoretical investigations on percussive drilling", Ph.D. Thesis (Unpublished), Indian Institute of Technology, Kharagpur, 1998.

[7] T.Szwedzicki, "Draft ISRM suggested method for determining the Indentation Hardness Index of Rock Materials", International Journal of Rock Mechanics and Mining Science, vol.35 (6), pp. 831-835, 1998.

[8] E.T. Brown, ISRM Rock characterization Testing and Monitoring Suggested methods, Pergamon Press, 198
[9] Adnan Aydin, "ISRM Suggested Method for Determination of the Schmidt Hammer Rebound Hardness: Revised Version", The ISRM Suggested Methods for Rock Characterization, Testing and Monitoring: 2007-2014, Ulusay13, pp.293-298, 2015.

[10] G.M. Alvarez, and R.Babuska, "Fuzzy model for the prediction of unconfined compressive strength of rock samples.” Int. J. Rock Mech. Min. Sci., vol. 36, pp. 339-349, 1999.

[11] J.Finol, Y.K.Guo and X.D.Jing. "A rule based fuzzy model for the prediction of petrophysical rock parameters.” J. Pet. Sci. Eng., vol.29, pp.97-113, 2001.

[12] C.Gokceoglu, "A fuzzy triangular chart to predict the uniaxial compressive strength of the Ankara Agglomerates from their petrographic composition." Eng. Geol., vol.66, pp.39-51, 2002

[13] I.Yilmaz, A.G.Yuksek,"Technical Note An Example of Artificial Neural Network (ANN) Application for Indirect Estimation of Rock Parameters". Rock Mechanics and Rock Engineering, vol. 41 (5), pp. 781-795, 2008

[14] I.Yilmaz, A.G.Yuksek, "Prediction of the strength and elasticity modulus of gypsum using multiple regression, ANN, and ANFIS models." International Journal of Rock Mechanics and Mining Sciences, vol. 46, pp. 803-810, 2009.

[15] Yilmaz and Oguz Kaynar," Multiple regressions, ANN (RBF, MLP) and ANFIS models for prediction of swell potential of clayey soils." Expert systems with Applications, vol. 38, pp. 5958-5966, 2011. 